\title{
Effect of Nursing Intervention on Activities of Daily Living of Older Adults with Chronic Respiratory Impairment
}

\author{
Amal Ibrahim Fouad ${ }^{1}$, Sahar Ahmed Shafik², Safia Belal ${ }^{3}$ \\ ${ }^{1}$ Community Health Nursing, Fayoum University, Fayoum, Egypt \\ ${ }^{2}$ Community Health Nursing, Helwan University, Helwan, Egypt \\ ${ }^{3}$ Critical Care Nursing, Saad Nursing College, Affiliated with Ulster University, Kouber, Saudi Arabia
}

Email address:

Sofy313@yahoo.com (S. Belal)

\section{To cite this article:}

Amal Ibrahim Fouad, Sahar Ahmed Shafik, Safia Belal. Effect of Nursing Intervention on Activities of Daily Living of Older Adults with Chronic Respiratory Impairment. American Journal of Nursing Science. Vol. 5, No. 4, 2016, pp. 129-140. doi: 10.11648/j.ajns.20160504.12

Received: May 25, 2016; Accepted: June 20, 2016; Published: July 6, 2016

\begin{abstract}
Background: Chronic respiratory impairment among older adults is associated with substation mortality, morbidity and was the third leading cause of death. Aim: Evaluate the effect of nursing intervention on ADL of older adults with chronic respiratory impairment. Design: A quasi-experimental design was used in this study. Sample: A purposive sample of 100 older adults patients with chronic respiratory impairment chosen from Government Hospital, half of them were study group and the other half was a control group. Tools: First: An interviewing questionnaire to assess demographic data, medical history and their knowledge. Second: An observational check list to assess their independency for activity of daily living. Third: A structured questionnaire to assess home environment. Results: Showed that there were highly statistical significant differences throughout intervention program phases (pre, post, and follow up) among the study group regarding their knowledge about chronic respiratory impairment, modify their home environment, and increase their independency level. The intervention had effect on their ADL, physical, psychological, and social conditions. Conclusion: There was a positive improvement compared with control group, and increasing the total satisfactory knowledge about chronic illness. Also increase the independency on practicing with ADL and enhancing psychological well-being among study group. The study recommended that: There is a need to increase of knowledge about; examination, checkup and follow up, simple modification of home environment to improve ventilation and degree of independence of daily activities such as bathing, grooming, dressing, precautions to infection prevention and social activities to improve the psychological status.
\end{abstract}

Keywords: Activity of Daily Living, Asthma, Chronic Bronchitis, Chronic Obstructive Pulmonary Diseases, Elderly

\section{Introduction}

Chronic pulmonary diseases are a debilitating disease affecting patients in daily life, both physically and emotionally. The associated symptoms such as dyspnea and muscle fatigue, lead to activity and exercise intolerance, which, together with behavioral issues, trigger physical inactivity. Physical impairment is associated with adverse clinical outcomes, including hospitalization and all can lead to serious complication, and mortality for the patients. Increasing activity levels is vital for effective management strategies and could lead to improved long-term outcomes for such group of patients. Chronic respiratory disorder are very common issue in Egypt which affect the quality of life for both male and female patients and has a relation with other disease, and its prevalence are increasing, especially among Egyptian female as other studies shown by [2]. According recent research reviews, in the world nearly around 300 million people affected with respiratory disorders in different ages and both genders. So through this study we will highlight at the activity of daily living for the people who suffer from chronic respiratory pulmonary disease. Moreover, the researchers will evaluate the effect of nursing intervention on activities of daily living of older adults with chronic respiratory impairment that help in guiding and add useful information to such group of patients, as it will enhance their health to coup with the disease. 


\subsection{Chronic Respiratory Impairment}

According to World health organization (WHO) in "[43] which defined of chronic obstructive pulmonary disease (COPD) as "a lung disease characterized by chronic obstruction of lung airflow that interferes with normal breathing and is not fully reversible". It is an illness condition usually progressive and associated with an abnormal inflammatory effect of the lungs to harmful particles or gases. The pathology of COPD contains chronic bronchitis and emphysema, although only one of these may be present in certain people with COPD. Chronic obstructive pulmonary disease is linked with major mortality and morbidity for example cardiovascular disease, type 2 diabetes, muscle wasting and asthma. [13, 22] explain the main cause of chronic obstructive pulmonary disease is tobacco smoke. Moreover, environmental reasons may also cause COPD especially with the patient who had long-term interaction with damaging pollutants in their work. Some of these damaging lung irritants contain fumes, dusts, or certain chemicals. Or other lung aggravations in the home, for example, organic cooking gas, may similarly cause COPD [6]. [41] add a little number of individuals has a rare form of COPD called as alpha-1 deficiency-related emphysema. This type of COPD is caused by a genetic situation that causes the body's ability to produce a protein (Alpha- 1) that protects the lungs. [32, 36] they are discussed In the primary phases of COPD, there may be no symptoms, or may only appear mild symptoms, for example, Shortness of breath, particularly with physical activity, a smoker's cough often called nagging cough, wheezing furthermore tightness in the chest. [24] clarify the treatment of COPD is generally focused on preventing more weakening and maintaining lung function and quality of life. As well as, just intervention that has been shown to slow the long term corrosion in lung function related with COPD is supporting smokers to quit and other treatment for COPD that can assistance to keep quality of life are oxygen therapy, drugs to control signs and symptoms and also to improve exercise tolerance such as anti-cholinergic that is opening the airways to reduce breathlessness and relax the muscles that surround the airways, and pulmonary rehabilitation.

\subsection{Activity of Daily Living with Respiratory Impairment}

ADLs and instrumental activities of daily living (IADLs) are greatly affected by respiratory impairment. Multiple studies conducted in different populations have demonstrated that respiratory impairment is associated with alterations in the person's social roles, relationships and self-perception which demands continual psychological adjustment [42]. While [41] add that the physical consequences of respiratory impairment range across a very broad spectrum, from the seemingly innocuous hindrance in performing activities of daily living (ADLs) to more obvious. These symptoms occur more often when lung disease cause significant limitation in activity and life style. The realization that one's breath is deteriorating and often associated with psychological reactions such as stress and anxiety, depression and low mood, panic, anger, frustration, guilt and life style change. Older adults with new respiratory impairment face a significant challenge at a time. They may also be experiencing other major life changes, such as general health limitations or the loss of a spouse [38, 40].

Older adult with respiratory impairment has also been found to have a negative impact on IADLs, physical functioning and social interaction. Older adults with respiratory impairment were twice as likely as those without respiratory impairment to have difficulties with ADLs (e.g., dressing, bathing, eating, getting in and out of bed) and IADLs (e.g., housekeeping, grocery shopping, food preparation). Data also support the fact that the level of decline in respiratory function, [21, 23]. While [3, 24] emphasizing on important for the nurse and health care professionals to understand normal physiological changes that occur with age and to know how to select teaching strategies to accommodate for normal aging changes and help patients follow medical recommendations by providing enough information, as well considering patients' individual needs, which agree with $[4,6,12]$ add this improving the ideas for building an awareness of community services that can help lessen social isolation, and helping them maintain their independence.

\subsection{Magnitude of the Problems}

Chronic respiratory impairment is a major public health problem in older adults over 60 years of age and will remain a challenge for the future. It is a major cause of chronic morbidity and mortality worldwide and is projected to rank seventh in 2030 as a worldwide burden of disease [3]. [36, 43] reported that prevalence of respiratory impairment among older adults is $47 \%$ worldwide and it is estimated that there may be an additional 100 million older adults with chronic respiratory impairment by 2020 and 250000 annual death, which is agree with [9] and [13]. According to world health organization estimates more than 3 million persons died of chronic obstructive pulmonary in 2012 which is equal to $6 \%$ of all deaths internationally in that year. In Egypt, the prevalence of chronic respiratory impairment for all ages is $68 \%$ of the population who are 60 years causing stiffness of the chest wall, weak muscles, or damaged nerves may cause the restriction in lung expansion [9]. Nearly half of all older adults with respiratory impairment will eventually enter a hospital as a result of being dependent in ADLs. Finally, nurses involved in almost all intervention programs for patients with respiratory impairment and play a crucial and specific role in the care, education and self-managements of patients with in such programs, [8] and [13]. This study will increase control over and enhance the health for such group of patients and also assist them how to manage illness.

\subsection{Aim of the Study}

The study aims to evaluate the effect of nursing intervention on ADLs of older adults with chronic respiratory impairment through: (1) Assessing the knowledge and 
independency in ADLs of older adults with chronic respiratory impairment. (2) Designing and implementing nursing intervention program according to their needs. (3) Evaluate the effect of nursing intervention program on knowledge, home environment and independency in ADLs of older adults with chronic respiratory impairment.

\subsection{Research Hypotheses}

The nursing intervention will improve the daily activity of older adults with chronic respiratory impairment.

\section{Subjects and Methods}

\subsection{Design and Setting}

Quasi-experimental research design was used to conduct this study. The study was conducted at outpatient clinic of governmental chest hospital at El-Abbasia city in Cairo. The clinic consists of large hall contains of 4 rooms, one for the consultant well equipped with the diagnostic devices, the second for measuring the pulmonary function, the third room for radiology and the forth room is for laboratory investigation. The majority of older adults with chronic respiratory impairment are treated at this hospital. This setting provides care to older adults with chronic respiratory impairment from all over the country and served about 27.200 older adults annually.

\subsection{Sample}

A purposive sampling sample was used to achieve the aim of the study. The study sample comprised of 100 older adults they represent about 5\% from the total attending the outpatient clinic in the period of, March, 2013 to January 2014. The patients have been selected according to following criteria: age 60 years and above, diagnosed with chronic respiratory impairment for at least one year, able to communicate and accept to participate in the study. The exclusion criteria were the patients not welling to participate in the study. The subjects were divided randomly into two groups, study and control groups each is composed of 50 patients.

\subsection{Data Sources}

The following tools were used in order to obtain necessary data:

\subsubsection{Questionnaire}

A self-administrative structured, anonymous interviewing questionnaire was developed by the researchers based on recent and related literatures from [18], [25], and [25], it was covering 27 items and it was designed to fit the Egyptian home environment. It was written in English language and translated to Arabic language to fit the participant criteria. Participants were informed about the aim of the study. Questionnaire included the following parts:

Part 1:

i. Socio-demographic characteristics of the studied sample: such as name, age, qualifications, gender, address, socioeconomic status, marital status,

ii. Medical status of older adults such as types of respiratory impairment, causes of disease, and treatment.

iii. Medical history about their health problems as smoking, secondary diagnosis, and mood disturbance due to respiratory impairment.

Part 2:

$i$. Questions to assess the older adults patient's level of knowledge regarding respiratory impairment which includes (aging changes, respiratory problems, asthma means, and types of chronic respiratory disorders).

ii. Questions regarding to their home environments included items related to cleaning, floor, lights, equipment's, machines, and the stair

\section{Scoring system}

A scoring system for older adults' knowledge was done as follows, each question had a group of answers points, each correct, complete answer scored had 2 marks which 1 mark for incomplete answer and zero for don't know or wrong answer. The total score for all questions related to knowledge was 24 marks which represents 100\%. The knowledge scores more categorized into three levels as follows: Good: more than or equal $70 \%$ of the total score 9 more than or equal to 15 marks). Average: $50-<70 \%$ (12-15 marks). Poor: less than $50 \%$ of the total score $(<12$ marks $)$.

\subsubsection{Checklist}

An observation checklist was designed to assess the study subjects as regards independence in daily living activities such as cooking, dressing, sleeping and practice exercises and psychological problems such as irritability, isolation, frustration and anxiety.

Scoring system:

The scoring system used for assessing independence regarding to daily living problem done as follows, each answer scored 4 marks for (no difficulty at all), 3 marks for (a little difficulty), 2 marks for (moderately difficulty), 1 marks for (extreme difficulty), and zero for (stooped doing this). Total score of this sheet had been 70 marks, which represents $100 \%$. Final it was be considered dependent if the percent score will be equal to or more than 42 points $(60 \%$ or more) and partially dependent if less than 42 points (less than 60\%) and totally dependent if zero. The scoring system used for assessing psychological problems done as follows, each answer scored 2 marks for (mild), 1 mark for (moderate), and zero for (severe). Total score for this sheet had been 8 marks, which represents $100 \%$. Final, it was be considered mild if the score will be more than or equal 4 marks, moderate if less than 4 marks and severe if zero.

\subsection{Validity and Reliability}

Validity was done through five experts, three of them from faculty staff of community health nursing and two nursing supervisors from respiratory units who reviewed the instruments. Pilot study was carried out on 10 older adults 
randomly selected with respiratory impairment fulfilling the selected criteria and was excluded from the study. Also it was done to test the reliability and applicability of the tools and to estimate the time required for interview. The tool was modified according [14], coefficient test was used to ascertain the reliability of the tool $(\mathrm{r}=0.087)$.

\subsection{Ethical Consideration}

Strict confidentiality was ensured throughout the data collection and intervention process; verbal approval was taken, purpose as well benefits of the study were informed to the participants, as well they told that the study is voluntary and they have the right to withdrawal at any time. The study subjects were assured that all data was used only for research purpose and details of participant's rights were informed.

\subsection{Field Work}

Official permissions were obtained from the directors of Fayoum University and director of Chest Hospital before conducting the study. After obtaining the official permissions to proceed with the study, data collection started and it took 10 months (March, 2013 - January, 2014). The researchers interviewed the patients individually in quiet and well ventilated room in the outpatient clinic to explain the purpose of the study and obtain verbal approval from them, also they were re-instructed this study is voluntary and they have the right to withdrawal at any time during the interview. The researchers filled in the structured questionnaire related to their demographic data which took from five to ten minutes. The questionnaire was filled by the first two researchers in outpatient clinic. Then, the third researcher started to examine the older adults' knowledge, and their independency in ADLs regarding respiratory impairment using prepared pre-test in the form of the questionnaire and observational checklist. The average time consumed in answering the knowledge questionnaire about thirty minutes duration, (the checklist filled by researcher). The researchers started to conduct the nursing intervention program after finishing the pre-test in the form of the questionnaire and observational checklist.

\subsection{Nursing Intervention Program Construction}

The nursing intervention program was constructed on four phases, assessment, planning followed by implementation and evaluation. The intervention program aims to evaluate the effect of nursing intervention on ADLs of older adults with chronic respiratory impairment.

\subsubsection{Assessment Phase}

The intervention program was designed by the researcher, based on the results of assessment (pretest and using the interviewing questionnaire and the observation checklists) as well as the literature review in order to provide the older adults with respiratory impairment with the required knowledge, and maintain their independency in daily living activities and modify their home environment.

\subsubsection{Content of the Nursing Intervention Program}

i. The aging process and problems of aging.

ii. The structure of respiratory system.

iii. Causes of respiratory disorders as asthma, chronic obstructive pulmonary disease, chronic bronchitis, emphysema, lung cancers, and tuberculosis.

iv. Maintain their independency in daily living activities and modify their home environment.

v. Improve independency of ADLs such as cooking, dressing, sleeping, practice exercises, home activity and bathing safely.

\subsubsection{Methods of Teaching and Audiovisual Aids}

This intervention program was conducted using a variety of teaching methods that included: lecture/ discussion, role play, demonstration and brain storming. Also the researcher used different audiovisual aids such as; data show, booklet, tap, pictures, real objects and booklet given to them.

The booklet included: Knowledge about the aging process and their problems, respiratory system problems and how to prevent its complications, how to maintain older adults' with respiratory impairment independent in their ADLs as much as possible, how to modify their home environment to meet their life diamonds.

\subsubsection{Implementation Phase}

It was carried out in the study group in the previously mentioned setting. The implementation of the intervention program composed of 13 separate main sessions ( 6 theories, 6 practice sessions and 1 revision for all contents) for the study group. Subjects were arranged into groups, each contained 10-12 older adults according to the available time of the older adults attending the outpatient clinic. The intervention program was implemented over a 4 months period, 3 sessions/ week; the duration of each session ranged from 30-40 minutes, followed by 5-10 minutes for a summary and discussion of what has been taught.

\subsubsection{Evaluation of the Intervention Program}

Evaluation of the intervention program was done immediately after the intervention program (posttest) and six months later (follow up) through testing the older adults' knowledge, and practice in relation their independency in daily living activities and modify their home environment.

\subsection{Statistical Analysis}

The collected data were tabulated and statistically analyzed using SPSS version 18.0 statistical software package. Data were presented using descriptive statistics in the form of frequencies and percentages for qualitative variables, and means and standard deviation for qualitative categorical variable using chi-square test and spearman rank correlation to identify the independent predictors of various scores, multiple stepwise backward regression analysis was used, and analysis of variance for the full regression models was done. Statistical significance was considered at $\mathrm{p}$-value $<0.05$. 


\section{Results}

Table 1: shows the socio-demographic characteristics of the study and control groups. It revealed that, $56 \%$ and $60 \%$ of study sample and control group respectively are between 65 and 70 years old, $58 \%$ of study group were males and $42 \%$ are females, while for the control group. $60 \%$ were males and $40 \%$ were females. Regarding to the level of education, both groups (study and control) had intermediate education $(74 \%$ and $70 \%$ respectively). Concerning monthly income, $28 \%$ and $32 \%$ of study and control group respectively didn't have enough monthly income. Regarding to marital status, the table shows that $60 \%, 64 \%$ were married, while $40 \%, 36 \%$ of both groups were widow/divorced and around half of older adults $(50 \%, 52 \%)$ lives in a nuclear family in the study and control group respectively.

Table (2) demonstrates that $90 \%$ and $86 \%$ of study sample and control group respectively had suitable home ventilation. $52 \%$ and $50 \%$ of study sample and control group respectively had 2 rooms. Regarding to the floor number $52 \%$ and $48 \%$ of the study sample and control group respectively had fourth floor number. Also, $82 \%$ and $80 \%$ of the study sample and control group respectively had automatic washes and $18 \%$ and $22 \%$ of the study sample and control group respectively had vacuum cleaner.

Table 3: Shows that $66 \%$ and $70 \%$ of study and control groups respectively had problems in both lungs. Regarding to the causes of respiratory disease, $48 \%$ and $52 \%$ had chronic respiratory disease, $38 \%$ and $26 \%$ had asthma in study and control group respectively. Also, there were statistical differences between both groups in all the items at $\mathrm{P}<0.05$.

Figure (1) shows that $42 \%$ and $44 \%$ use drugs, while $58 \%$ $\& 56 \%$ use chemo- therapy for their treatment for study and control groups respectively.

Table 4: Illustrate the health problems among study and control groups, it shows that $40 \%$ and $44 \%$ were smokers, $90 \%$ and $84 \%$ had arthritis for study and control groups respectively. Also, $82 \%$ and $80 \%$ of the study sample and control group respectively had depressed mood.

Table 5: illustrates that $60 \%$ of the studied sample had moderate difficulties in cooking, bathing, $90 \%$ of females stopped doing exercises', while $60 \%$ had extreme difficulties in dressing. Also, 50\% had a little difficulty to dressing, all of females stopped home activity. Regarding going down and upstairs, $40 \%$ and $16 \%$ had moderate difficulties, $60 \%$ had extreme difficulty in bathing and 54\% stopped doing up stairs. Concerning found in crowded places $44 \%$ and $50 \%$ stopped to be found in crowded places. There were no significant differences between both groups as regard all daily living problems except in dressing, home activity, toileting and getting down stairs at $\mathrm{P}>0.05$.

Figure (2): shows distribution of the study sample regarding to psychological problems. The majority of the studied sample $90 \%$ had moderate isolation and most of them $80 \%$ had moderate frustration respectively. Also, the figure shows that less than two third of the studied sample $60 \%$ had severe anxiety.

Table (6): Describe the level of knowledge pre, post and follow up the intervention program among study and control groups. It shows that, $18 \%$ of study group had good knowledge for aging changes in preprogram, improved to good ( $86 \%$ and $90 \%$ respectively) after and follow up the intervention program, while $16 \%$ and $15 \%$ of the control group had good knowledge before and after intervention program. Regarding respiratory health problems, $38 \%$ of the study group had good knowledge in pre-program and changed to be $(98 \%)$ in post-program, while $35 \%, 36 \%$ \& $64 \%$ respectively of the control group had good knowledge in pre, post and follow up the intervention program.

Concerning Asthma, it shows that $100 \%$ had poor knowledge in pre intervention program among study and control groups, but improved to be good $60 \%$ in study group only. Regarding to the prevention of the complications, $30 \%$ had good knowledge among study and control groups in preprogram, while they improved to be $84 \%$ in follow up of study group and $72 \%$ in control group for all phases. There were significant differences between all knowledge items except for chronic obstructive pulmonary disease meaning at $\mathrm{P}<0.05$.

Table 7: Shows that there are statistical significant differences between both groups regarding ADLs independency. Regarding home activity, $80 \%$ of the study group do home activity post program compared to $12 \%$ pre the program while it was $11 \%$ of control group even after the follow up. Concerning preparing meal, $20 \%$ of study group was good in pre-program improved to be $82 \%$ in the follow up phase, while it was $22 \%$ of control group in follow up. Concerning getting up or down the stairs safely $22 \%$ of the study group improved to be $90 \%$ in follow up while it was $22 \%$ of control group in follow up at $\mathrm{P}<0.05$.

Table 8: shows significant relation between knowledge about disease and ADLs pre, post and follow up the intervention program for study and control groups. It was found that, a significant value between pre, post and follow up the intervention program in study group (mean $\pm \mathrm{SD}=$ $12.800 \pm 3.523)$ in pre and improved to be $(19.560 \pm 4.057)$ in post intervention program and $(17.660 \pm 2.044)$ in follow up but no significant value between pre and post in control group.

Table 9: showed that, the modification of home environment was effective on independency with the ADLs pre, post and follow up the intervention program for study and control groups, it was found that there was a significant difference between pre, post and follow up the intervention program in study group (mean $\pm \mathrm{SD}=4.500 \pm 2.053$ ) in pre and improved to $(8.040 \pm 1.009)$ and P-value $<0.001$ in post and $(7.030 \pm 2.040)$ in follow up the intervention program but no significant difference between pre, post and follow up in control group. 
Table 1. Distribution of the study sample regarding to socio demographic characteristics $(n=100)$.

\begin{tabular}{lll}
\hline Item & Study $\mathbf{N}=\mathbf{5 0}(\mathbf{\%})$ & Control $\mathbf{n}=\mathbf{5 0}(\mathbf{\%})$ \\
\hline Age group (years): & 20 & 24 \\
$60-$ & 56 & 60 \\
$65-$ & 24 & 16 \\
$70+$ & $60.125 \pm 7.546$ & \\
Mean SD & & 60 \\
Gender: & 58 & 40 \\
Male & 42 & \\
Female & & 4 \\
Education: & 2 & 70 \\
Primary education & 74 & 26 \\
Intermediate education & 24 & \\
High education & & 64 \\
Marital status: & 60 & 16 \\
Married & 14 & 20 \\
Single: widowed & 26 & \\
Divorced & & 32 \\
Monthly income & 28 & 68 \\
Not enough & 72 & 52 \\
Enough & & 48 \\
Type of family & 50 & \\
Nuclear & 50 & \\
Extended & &
\end{tabular}

Table 2. Distribution of the study sample regarding to assessment of home environment for older adults with respiratory impairment through asking questions $(n=100)$.

\begin{tabular}{|c|c|c|}
\hline Item & Study N=50 (\%) & Control $n=50(\%)$ \\
\hline \multicolumn{3}{|l|}{ Home ventilation: } \\
\hline Suitable. & 90.00 & 86.00 \\
\hline Not suitable. & 10.00 & 14.00 \\
\hline \multicolumn{3}{|l|}{ Number of rooms } \\
\hline Two & 52.00 & 50.00 \\
\hline Three & 40.00 & 42.00 \\
\hline Four & 8.00 & 08.00 \\
\hline Separate bath room & 100.00 & 50.00 \\
\hline \multicolumn{3}{|l|}{ Floor number } \\
\hline Two & 18.00 & 20.00 \\
\hline Three & 26.00 & 24.00 \\
\hline Four & 52.00 & 48.00 \\
\hline Five & 4.00 & 08.00 \\
\hline \multicolumn{3}{|c|}{ Equipment and machine } \\
\hline Ordinary washes & 36.00 & 40.00 \\
\hline Automatic washes & 82.00 & 80.00 \\
\hline Conditioner & 18.00 & 20.00 \\
\hline Fan & 22.00 & 24.00 \\
\hline Heater & 50.00 & 90.00 \\
\hline Vacuum cleaner & 18.00 & 22.00 \\
\hline TV & 100.00 & 100.00 \\
\hline Computer & 50.00 & 52.00 \\
\hline
\end{tabular}

Total items not mutually exclusive 
Table 3. Distribution of the study sample regarding to physical examination: $(n=100)$.

\begin{tabular}{|c|c|c|c|c|}
\hline \multirow{2}{*}{ Item } & \multirow{2}{*}{ Study N=50 (\%) } & \multirow{2}{*}{ Control $n=50(\%)$} & \multicolumn{2}{|c|}{ Chi-square } \\
\hline & & & $\mathbf{X}^{2}$ & P value \\
\hline \multicolumn{5}{|l|}{ The problem in: } \\
\hline One lung & 34.00 & 30.00 & 5.120 & $0.024 \mathrm{~s}$ \\
\hline Two lungs & 66.00 & 70.00 & & \\
\hline The causes: & 48.00 & 52.00 & 23.120 & $0.000 \mathrm{~s}$ \\
\hline \multicolumn{5}{|c|}{-Chronis obstructive pulmonary disease. } \\
\hline -Asthma & 38.00 & 26.00 & & \\
\hline -Chronic bronchitis & 2.00 & 4.00 & & \\
\hline Lung cancer & 18.00 & 16.00 & & \\
\hline
\end{tabular}

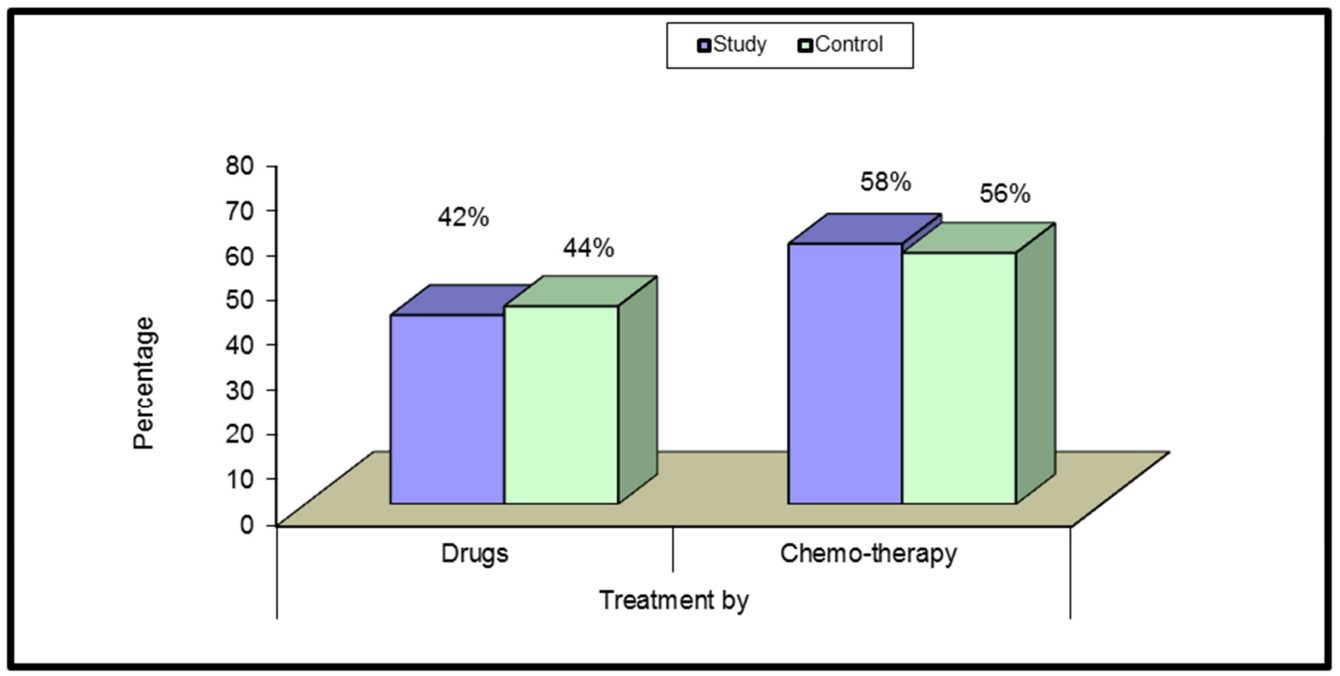

Figure 1. Distribution of the study sample regarding to treatment.

Table 4. Distribution of the study sample regarding to their health problems $(n=100)$.

\begin{tabular}{|c|c|c|}
\hline Item & Study $N=50(\%)$ & Control $\mathrm{n}=50(\%)$ \\
\hline \multicolumn{3}{|l|}{ Smoker } \\
\hline Secondary diagnosis & 40 & 44 \\
\hline Diabetes & 76 & 80 \\
\hline Coronary arteries & 40 & 36 \\
\hline Arthritis & 90 & 84 \\
\hline High blood pressure & 44 & 40 \\
\hline Osteoporosis & 40 & 40 \\
\hline \multicolumn{3}{|l|}{ Cancer } \\
\hline Cardiac disease & 36 & 32 \\
\hline Mood & 24 & 28 \\
\hline Cheerful & 18 & 20 \\
\hline Depressed & 82 & 80 \\
\hline
\end{tabular}

Total items not mutually exclusive.

Table 5. Distribution of the study sample regarding to daily living problems $(n=100)$.

\begin{tabular}{|c|c|c|c|c|c|c|c|}
\hline \multirow[t]{2}{*}{ Daily living problems } & \multirow{2}{*}{$\begin{array}{l}\text { No difficulty at all } \\
\%\end{array}$} & \multirow{2}{*}{$\begin{array}{l}\text { A little } \\
\text { difficulty }\end{array}$} & \multirow{2}{*}{$\begin{array}{l}\text { Moderately difficulty } \\
\% \\
\end{array}$} & \multirow{2}{*}{$\begin{array}{l}\begin{array}{l}\text { Extreme } \\
\text { difficulty }\end{array} \\
\%\end{array}$} & \multirow{2}{*}{$\begin{array}{l}\begin{array}{l}\text { Stopped } \\
\text { doing this }\end{array} \\
\%\end{array}$} & \multicolumn{2}{|c|}{ Chi-square } \\
\hline & & & & & & $\mathbf{X}^{2}$ & P value \\
\hline Cooking & - & & 60.00 & 20.00 & 20.00 & 2.000 & 0.157 \\
\hline Practice exercises & - & - & - & 10.00 & 90.00 & 2.000 & 0.157 \\
\hline Bathing safely & - & - & 20 & 60.00 & 10 & 34.000 & $0.000 \mathrm{~s}$ \\
\hline Dressing & - & 10 & 36.0 & - & - & 13.000 & $0.002 \mathrm{~s}$ \\
\hline Home activity & 14.00 & 50.00 & - & - & 100.00 & 13.000 & $0.002 \mathrm{~s}$ \\
\hline Found in crowded places & - & - & 20.00 & 36.00 & 44.00 & 2.000 & 0.157 \\
\hline Grooming & - & - & 60.00 & 40.00 & - & 2.000 & 0.157 \\
\hline Toiletig & - & - & 64.00 & 6.00 & - & 19.000 & $0.000 \mathrm{~s}$ \\
\hline Sleeping deeply & - & 30 & 40.00 & 30 & - & 1.000 & 0.607 \\
\hline Drinking & - & 30 & 40.00 & 60 & - & 2.000 & 0.157 \\
\hline Going down stairs & - & - & 40.00 & 30 & - & 1.000 & 0.607 \\
\hline Going up stairs & - & 30 & 16.00 & 30.00 & 54.00 & 13.000 & $0.002 \mathrm{~s}$ \\
\hline
\end{tabular}




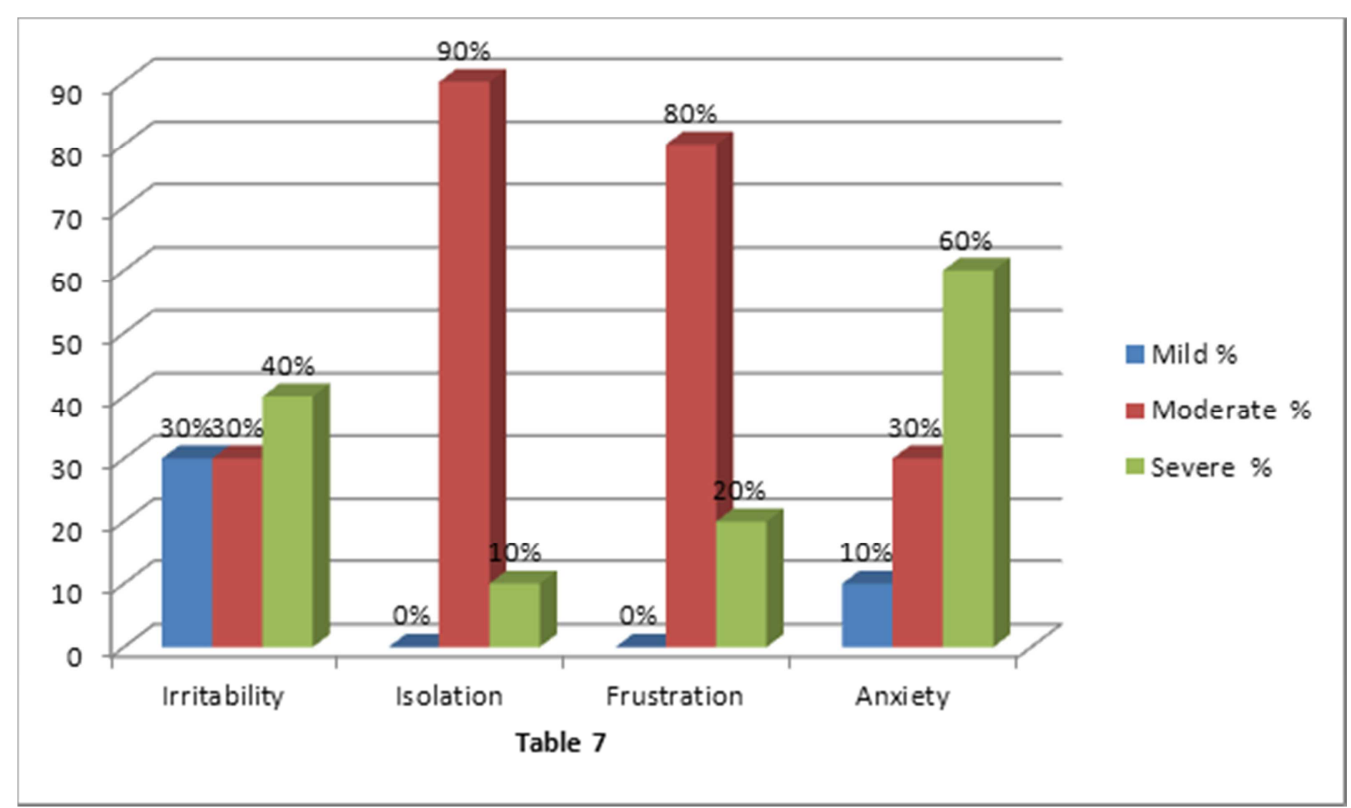

Figure 2. Distribution of the study sample regarding to psychological problems ( $n=100)$.

Table 6. Distribution of the study according to good knowledge about respiratory disease in elders among the study and control group throughout program phases.

\begin{tabular}{|c|c|c|c|c|c|c|c|c|}
\hline \multirow{3}{*}{ Knowledge } & \multicolumn{8}{|c|}{ Program phase } \\
\hline & \multicolumn{3}{|c|}{ Study (50) } & \multicolumn{3}{|c|}{ Control (50) } & \multicolumn{2}{|c|}{ Chi-Square } \\
\hline & Pre Good\% & $\begin{array}{l}\text { Post } \\
\text { Good\% }\end{array}$ & $\begin{array}{l}\text { Follow up } \\
\text { Good\% }\end{array}$ & $\begin{array}{l}\text { Pre } \\
\text { Good\% }\end{array}$ & $\begin{array}{l}\text { Post } \\
\text { Good\% }\end{array}$ & $\begin{array}{l}\text { Follow up } \\
\text { Good\% }\end{array}$ & $\mathbf{X}^{2}$ & P value \\
\hline Aging changes & 18.00 & 86.00 & 90.00 & 16.00 & 15.00 & 16.00 & 9.225 & $0.010 \mathrm{~s}$ \\
\hline Aging changes factors & 0.00 & 44.00 & 47.00 & 0.00 & 0.00 & 100.00 & 31.022 & $0.000 \mathrm{~s}$ \\
\hline Chest contains & 20.00 & 42.00 & 45.00 & 19.00 & 20.00 & 80.00 & 8.197 & $0.017 \mathrm{~s}$ \\
\hline Respiratory problems & 38.00 & 98.00 & 98.00 & 35.00 & 36.00 & 64.00 & 5.334 & $0.069 \mathrm{~s}$ \\
\hline Asthma means & 0.00 & 60.00 & 65.00 & 0.00 & 0.00 & 100.00 & 32.415 & $0.000 \mathrm{~s}$ \\
\hline COPD means & 34.00 & 86.00 & 85.00 & 32.00 & 33.00 & 67.00 & 4.123 & 0.127 \\
\hline Types of COPD & 4.00 & 60.00 & 64.00 & 5.00 & 4.00 & 96.00 & 27.105 & $0.000 \mathrm{~s}$ \\
\hline Normal respiratory pattern & 5.00 & 43.00 & 45.00 & 6.00 & 5.00 & 95.00 & 22.969 & $0.000 \mathrm{~s}$ \\
\hline To keep level of respiration & 2.00 & 92.00 & 95.00 & 3.00 & 4.00 & 96.00 & 30.717 & $0.000 \mathrm{~s}$ \\
\hline The risk group for lung cancer & 18.00 & 84.00 & 85.00 & 18.00 & 9.00 & 91.00 & 15.003 & $0.001 \mathrm{~s}$ \\
\hline Factors effects on increase lung cancer & 30.00 & 80.00 & 85.00 & 31.00 & 30.00 & 70.00 & 6.209 & $0.045 \mathrm{~s}$ \\
\hline How to prevent the complication & 30.00 & 80.00 & 84.00 & 28.00 & 28.00 & 72.00 & 6.525 & $0.038 \mathrm{~s}$ \\
\hline
\end{tabular}

Table 7. Distribution of independency in daily living activities throughout program phases among study and control groups ( $n=50)$.

\begin{tabular}{|c|c|c|c|c|c|c|c|c|}
\hline \multirow{3}{*}{$\begin{array}{l}\text { Daily living activities } \\
\text { (independency) }\end{array}$} & \multicolumn{8}{|c|}{ Program phase } \\
\hline & \multicolumn{3}{|c|}{ Study (50) } & \multicolumn{3}{|c|}{ Control (50) } & \multicolumn{2}{|c|}{ Chi-Square } \\
\hline & Pre Good\% & Post Good\% & Follow up Good\% & $\begin{array}{l}\text { Pre } \\
\text { Good\% }\end{array}$ & $\begin{array}{l}\text { Post } \\
\text { Good\% }\end{array}$ & $\begin{array}{l}\text { Follow up } \\
\text { Good\% }\end{array}$ & $\mathbf{X}^{2}$ & Pvalue \\
\hline Home activity & 12.00 & 80.00 & 80.00 & 13.00 & 12.00 & 11.00 & 12.795 & $0.002 \mathrm{~s}$ \\
\hline Bathing safety & 40.00 & 100.00 & 100.00 & 45.00 & 42.00 & 40.00 & 8.671 & $0.013 \mathrm{~s}$ \\
\hline Dressing the clothes safety & 44.00 & 100.00 & 100.00 & 45.00 & 46.00 & 45.00 & 5.729 & $0.057 \mathrm{~s}$ \\
\hline Preparing the meal & 20.00 & 80.00 & 82.00 & 22.00 & 23.00 & 22.00 & 8.131 & $0.017 \mathrm{~s}$ \\
\hline Up or down stair safety & 22.00 & 90.00 & 90.00 & 23.00 & 22.00 & 22.00 & 10.717 & $0.005 \mathrm{~s}$ \\
\hline
\end{tabular}

Table 8. Relation between the knowledge about respiratory impairment and ADL pre and post the nursing intervention program for study and control groups $(n=100)$.

\begin{tabular}{|c|c|c|c|c|c|c|c|}
\hline \multirow{3}{*}{ ADL } & & \multicolumn{4}{|c|}{ The knowledge about respiratory impairment } & \multicolumn{2}{|l|}{ T-test } \\
\hline & & \multicolumn{2}{|c|}{ Study 1} & \multicolumn{2}{|l|}{ Control } & \multirow[b]{2}{*}{$\mathbf{T}$} & \multirow[t]{2}{*}{ P-value } \\
\hline & & Mean & SD & Mean & SD & & \\
\hline \multirow{3}{*}{\multicolumn{2}{|c|}{$\begin{array}{l}\text { Pre } \\
\text { Post } \\
\text { Follow-up }\end{array}$}} & 12.800 & 3.523 & 11.545 & 2.995 & 1.919 & 0.0579 \\
\hline & & 19.560 & 4.057 & 13.215 & 2.15 & 9.772 & $<0.001 \mathrm{~s}$ \\
\hline & & 17.660 & 2.044 & 10.434 & 2.01 & 8.663 & $<0.001 \mathrm{~s}$ \\
\hline \multirow{2}{*}{ Paired t-test } & $\mathrm{T}$ & -8.394 & & -1.54 & & & \\
\hline & $P$ value & $<0.001 \mathrm{~s}$ & & 0.084 & & & \\
\hline
\end{tabular}


Table 9. Relation between modification of home environment with independency in ADLs for older adults with respiratory impairment ( $\mathrm{n}=100)$.

\begin{tabular}{|c|c|c|c|c|c|c|c|}
\hline \multirow{3}{*}{\multicolumn{2}{|c|}{ Independency in ADLs }} & \multicolumn{4}{|c|}{ Modification of home environment } & \multicolumn{2}{|l|}{ T-test } \\
\hline & & \multicolumn{2}{|c|}{ Study 1} & \multicolumn{2}{|c|}{ Control } & \multirow{2}{*}{\multicolumn{2}{|c|}{ P-value }} \\
\hline & & Mean & SD & Mean & SD & & \\
\hline Pre & & 4.500 & 2.053 & 3.95 & 1.845 & 1.409 & 0.162 \\
\hline Post & & 8.040 & 1.009 & 4.12 & 2.150 & 11.671 & $<0.001 *$ \\
\hline Follow-up & & 7.030 & 2.040 & 3.94 & 1.642 & 10.561 & $<0.001 *$ \\
\hline \multirow{2}{*}{ Paired t-test } & $\mathrm{T}$ & -10.735 & & -1.14 & & & \\
\hline & $P$ value & $<0.001 *$ & & 0.284 & & & \\
\hline
\end{tabular}

\section{Discussion}

The purposes of intervention for older adults with respiratory impairment are to increase exercises tolerances reduce symptoms of breathlessness, and to improve function in daily activities [13]. According to socio-demographic characteristics of study and control groups (table 1) shows that approximately more than one half of study and control groups were males. This supported a finding by [1] who stated, each year about 20,000 male is more than female complaining from respiratory disorder. Also, a slightly higher incidence of developing respiratory infection than female. Regarding age, most of the elder with respiratory disorder in study and control group were over 65 years old, on the same point $[6,9]$ emphasized that $52 \%$ of persons aged 65 yrs., and over have chronic respiratory disease.

It was reported by [30] that the acuity-worse than $20 / 40$ occurs an as many as $21 \%$ of persons aged 65 yrs., or older. The pulmonary function test (Pulmonary function test) project, which studied 2520 individuals, aged 65 yrs., to 84 yrs. found that the prevalence of respiratory function acuity was worse them $20 / 20$ to be $11.4 \%$ in the white Americans and $16.4 \%$ in the black Americans studied.

The Beaver Dan respiratory study according to [10] which examined 4926 persons aged 43 to 86 yrs., found that the best - corrected respiratory acuity which is worse than $20 / 40$ occurred in $21.1 \%$ of those aged $65 \mathrm{yrs}$. and older, in $5.0 \%$ of those between 69 and 74 yrs., in $0.9 \%$ of those between 65 and 70 yrs., and in $0.8 \%$ of those between 48 and 75 yrs. Concerning educational level, almost three quarter of both group had intermediate education, while $[9,23]$ reported that, the educational level was not strongly inversely associated with respiratory disorders otherwise there was even amore distinct gradient of decreasing risk with increasing level of education.

The result revealed that, about one third of the studied sample had not enough income for study control group and had no financial support. This finding was in disagreement with $[15,27]$ stated that, financial status is an important risk factor for respiratory disorder, with incidence and increase cases of respiratory cancer.

The present study demonstrates that most of the study sample and control group had automatic washes and less than one quarter of the study sample and control group had vacuum cleaner Table (2). It supported by [7] who stated that, using of equipment $\&$ machine at home like automatic washes $\&$ vacuum cleaner are also important for people with impaired respiration to function independently and safely at home. People who are with respiratory impairment must make their environmental modifications within the home. It can also assess the environment for safety and ease of functioning. It could be noted that modifications are usually easy to carry out because they typically involve no-or low-cost changes which make it possible for older people with a range of personal incomes.

Regarding the causes of respiratory disorder table (3) it was found that, one half of the study and control group had chronic obstructive pulmonary disease on the same point [33] stated that the older adults had chronic obstructive pulmonary disease with a percentage of the general population between the age of 65 and 75 yrs., has chronic obstructive pulmonary disease, and that number increased by $20 \%$ after age of 75 yrs. Also, around one third of study and control group had Asthma, this finding was in agreement with [31] who stated that $30 \%$ of older adults had respiratory disorders including Asthma, Bronchitis and chronic obstructive pulmonary disease, while [36, 38] reported that, the most prominent pathologies under aging respiratory disease and lung cancer among the older adults Medicare population found that they had Asthma, Bronchitis \& chronic obstructive pulmonary disease.

Concerning the treatment about less than half were taking drugs while more than one half were using chemotherapy in treatment figure (1). In the same point $[10,20]$ mentioned that for most patients, periodic observation and frequent drugs prescription changes are sufficient and surgery is not necessary.

Regarding health problems of the studied sample table (4) around less than one half of the present study were smokers [5] stated that the lung cancer tends to occur more frequently in persons who smoke. Even after treatment, smokers are reported to have a greater chance of having lung cancer reoccur. Also, the present study revealed that, most of study \& control groups had diabetes, in the same point, [8] supported that diabetes have a devastating effect on many organs \& tissues if blood glucose is not carefully controlled.

Regarding to the study of older adults' mood, it revealed that more than three quarters were depressed, this result was in agreement with [32] who found that impaired respiratory and depression both associated strongly with functional impairment and concluded that treating depression might reduce excess disability can cause secondary grief, anxiety, and depressed mood. These non-respirations, also consequences of respiration impairment can worsen or precipitate clinical depression in the older adults' person. 
Regarding to daily living problems, table (5) showed that less than one quarter had extreme difficulty during cooking and one third stopped doing it while, the most of them stopped doing exercises, one third have extreme difficulty in bathing safely. This was supported by [21] who stated that according to the studied 246 patients, they had the same similar problems; which are complaints caused by respiratory problem the three most common components of each problem were difficulty of performance (13\%), psychological distress associated with performance of the activity of daily living (11\%).

One the same point $[12,13]$ stated that respiratory disease can cause troubles in maintaining their independence and completing typical day to day activities. This was supported by [30] in established population for the Epidemiologic Studies of the Elderly, a population-based study of 5143 older adults persons, $26 \%$ of 577 individuals with limitation in ADLs (Activity of daily Living) were found to be respiratory impaired. The Massachusetts Health Care Panel Study of no institutionalized elderly persons reported 289 with good respiration and 207 with self-perceived respiratory impairment. The respiratory impairment group was 2.3 times more likely than the group with good respiration to need help in house work and 1.68 times more likely to need help in crowded places [27] surveyed 103 nursing home residents for residents for ADL function and found a strong linked between respiratory disease and $\mathrm{ADL}$ disability; they also found that residents' ADL dependency was significantly related to the presence of respiratory disorders. [11] stated that the older adults with respiratory impairment were found to be three to four times more likely to have difficulty in walking, going outside, and getting in and out of bed. These and others studies have shown that there is a relationship between respiratory impairment and loss of independence.

Concerning the independency with daily activities before and after the intervention program it was revealed that, more than one third had a moderate difficulty in dressing. It was supported by $[22,23]$ they found that, these are basic things that everyone does on daily basis: maintaining hygiene (bathing, grooming, and mouth care), dressing, eating (the ability to feed oneself), toileting (the ability to use a restroom), transferring (moving out of bed). When one or more of these activities is impaired, the need for care offering help is obvious and urgent. [38, 39] mentioned that functional limitation in the ability to carry out daily activities as a result of respiratory impairment is one of the most important measures of outcomes because it represents the impact of respiratory impairment on individuals in their daily lives.

Concerning the psychological problems of the sample group (figure 2), it was found that less than one third of the sample had mild irritability, while most of them felt moderate isolation and frustration and more than one half had sever anxiety. On the same point, [27] said that, the older adults with respiratory impairment are feeling or persisting sadness and anxiety, loss of interest or pleasure in ordinary activities, including sex, and sleep problems (difficulty getting to sleep or sleeping too much). This psychological problem could be illustrated owing to the respiratory problem beside other factors as their unstable social relations, which is proved by having less than one half of the study sample were actually unmarried leading to the feeling of independence.

Concerning the effect of intervention program on older adults with respiratory impairment in the study sample, this study showed that there was statistically significant differences throughout intervention program phases (pre, post, and follow up) among the study group regarding their knowledge about respiratory disorder related to main items (definition, predisposing factor, signs and symptoms, types, diagnosis, treatment, precaution and how to prevent complications) (table 6). [16, 19] stated that, the majority of people aged 65 and older with respiratory impairment are unaware of services and devices that could help them to improve their independency in ADL. The need for information will increase as the number of older adults who are at greatest risk, who are aged 65 and older.

As showed in the table (7), for preparing the meal the less than one quarter was good in the pre-program, which is improved to be more than three quarter was good. But for ascending and descending the stairs safely, less than one quarter was good, but this improved to have the majority of them in the post and follow up the intervention programs. [41] pointed that, it is possible for people with respiratory impairments to continue to live independent and continue living in their own homes and complete daily tasks, such as showering, dressing, cooking, grocery shopping, managing finances, and getting around in the community.

Relation between knowledge about disease and the ADL before and after the intervention program for study and control groups (Table 8). It was found that, a significant value between pre, post and follow up the intervention program in study group (mean $\pm \mathrm{SD}=12.800 \pm 3.523$ ) in pre and improved to be $(19.560 \pm 4.057)$ in post intervention program and $(17.660 \pm 2.044)$ in follow up but no significant value between pre and post in control group.

However, these findings were in consistent with [33] who evaluated personalized booklets which were distributed at discharge and contained individualized information about symptoms, advice on activities of daily living, and local and national contacts. No differences were found in basic or extended activities of daily living, $50 \%$ of the participants who learned about knowledge respiratory disorder got satisfaction and felt that the booklet was useful. From the point of view of the researcher the current study showed statistically significant differences throughout intervention program phases among study subjects regarding knowledge about prevention of complications of the disease. This may be that they felt worried and anxious about what will happen in case of having complications that affect their independency in ADLs.

(Table 9) showed that, the modification of home environment was effective on independency with the ADLs pre, post and follow up the intervention program for study and control groups, it was found that there was a significant difference between pre, post and follow up the intervention program in study group (mean $\pm \mathrm{SD}=4.500 \pm 2.053$ ) in pre 
and improved to $(8.040 \pm 1.009)$ and $\mathrm{P}$-value $<0.001$ in post and $(7.030 \pm 2.040)$ in follow up the intervention program but no significant difference between pre, post and follow up in control group.

This was supported by $[17,20]$ they reported that, the program teacher who provides independent living skills training in the home of the person with respiratory disease can also assess the environment for safety and ease of functioning. Suggestions for modifications are usually easy to carry out because they typically involve no or low cost changes which make it possible or older people with a range of personal incomes. In the same point [22] reported a significant reduction in the incidence of dyspnea and asthma after successful intervention study, which consisted of a multi-factorial fall prevention program comprising staff education, environmental adjustment, exercises, drug review, aids and problem solving conferences. [29, 35] noted that, within the respiratory disorders, rehabilitation teachers, professionals who teach adaptive techniques for independent living, work with people who are respiratory impaired to make these environmental modifications within the home and in the workplace.

\section{Conclusion}

According to the results and the research hypothesis; the study conducted that, there was a statistical significant relation between knowledge about respiratory impairment and independency in ADLs pre and post the nursing intervention program for study and control groups. It was found that, a significant value between pre and post nursing intervention program in study group (mean $\pm \mathrm{SD}=12.800 \pm 3.523$ ) in pre intervention and improved to be $(19.560 \pm 4.057)$ in post intervention program but no significant value between pre and post in control group.

\section{Recommendations}

Taking into consideration the results of the current study, it is recommended to:

Increase the respiratory impairment older adult's knowledge about the periodic examination and follow up continuously. Simple modification of home environment to improve ventilation and degree of independence of daily activities such as bathing, grooming, dressing, cooking, and practice exercises. Apply the precautions of infection control. Encourage social activities to improve the psychological status. Future researchers required to detect the long-term effect of needs of older adults with chronic respiratory impairment.

\section{Acknowledgements}

The authors wish to sincerely thank all nurses and patients participate in the study and who were willing to share their experiences from the impact of teaching intervention. Also we need to extend our thinks to the dean of Fayoum Nursing College for his continuous support

\section{References}

[1] Abyad A., (2012): In office screening for age related C. O. P. D and Asthma loss. Geriatrics, 52, 45-54.

[2] Adams E, Flynn K, Alligood E, and Johnson T., (2013): Optical devices for adults with low vision: a systematic review of published studies of effectiveness. Final report. Boston (MA): VA Technology Assessment Program, Office of Patient Care Services. P 46.

[3] Alonso J, Espallargues M, Andersen TF, Cassard SD, Dunn E, Bernth-Petersen P, Norregaard JC, Black C, Steinberg EP, and Anderson GF., (2012): International applicability of the VF-14: an index of lung function in patients with C. O. P. D; 104: 799807.

[4] Bachelder J. and Harkins D. Jr., (2015): Do occupational therapists have a primary role in respiratory disorder rehabilitation? American Journal of Occupational Therapy, 49, 927-930.

[5] Bergner M, Bobbitt R. A, Carter W. B, and Gilson B. S., (2010): The Sickness Impact Profile: development and final revision of a health status measure. Med Care; 19: 787-805.

[6] Bookman A, Harrington M, Pass L, and Reisner E., (2011): Family Caregiver Handbook. Cambridge, MA: Massachusetts Institute of Technology.

[7] Brabyn J, Schneck M, Haegerstrom-Portnoy G, and Lott L., (2014): The Smith-Kettlewell Institute (SKI) longitudinal study of vision function and its impact among the elderly: an overview. Optom Vis Sci. 78 (5): 264-9.

[8] Elam J. T, Graney M. J, Beaver T, el Derwi D., Applegate W. B, and Miller S. T., (2012): Comparison of subjective ratings of function with observed functional ability of frail older persons. Am J Public Health; 81: 1127-30.

[9] Ezz A. L Arab R. J, Welsh R. L, Lewis L. J., (2014): Improving the Well bing of respiratory impaired older adults through orientation and mobility training and rehabilitation: an evaluation. RE: view; 32 (2): 67-76.

[10] Faye E., (2012): Living with respiratory disorder. Postgraduate Mdicine, 103: 167-178.

[11] Foran S, Mitchell P, and Wang J. J., (2013): Five year change in visual acuity and incidence of visual impairment: the Blue Mountains Eye Study. Ophthalmology; 110 (1): 41-50.

[12] Frost N. A, Sparrow J. M, Durant J. S, Donovan J. L, Peters T. J, and Brookes S. T., (2012): Development of a questionnaire for measurement of vision related quality of life. Ophthalmic Epidemiol; 5: 185-210.

[13] Guyatt, (2014): Impact of respiratory impairment on health related quality of life: the Blue Mountains lung Study. Invest Ophthalmol Vis Sci; 45 (1): 71-6.

[14] Gronbach Alppha, (1951): A tool for assessing the reliability of scales.

[15] Hall J. A, Epstein A. M, and McNeil B. J., (2012): Multi dimensionality of health status in an elderly population: construct validity of a measurement battery. Med Care; 27: S168-77. 
[16] Harris R. P, Helfand M, Woolf S. H, Lohr K. N, Mulrow C. D, Teutsch S. M, and Atkins D., (2014): Current methods of the U.S Preventive Services Task Force. A review of the process. Am J Prev Med; 20 (3 Suppl): 21-35.

[17] Harwood R. H., (2011): Visual problems and falls. Age Ageing; 30 Suppl 4: 13-8.

[18] Hoffman L. G, Rouse M. W, Brin B. N., (2013): Quality of life: a review. J Am Optom Assoc; 66: 281-9.

[19] Lamoureux E. L, Hassell J. B, and Keeffe J. E., (2013): The determinants of participation in activities of daily living in people with impaired PFT. Am J; 137 (2): 265-70.

[20] Lomas J, Pickard L, and Mhide A., (2013): Patient versus clinician item generation for quality of life measures: the case of language disabled adults. Med Care; 25: 764-9.

[21] Long R. G, Crews J. E, and Mancil R., (2011): Creating measures of rehabilitation outcomes for people who are respiratory impaired: the FIMBA project; 94: 292-306.

[22] Lord S. R and Dayhew J., (2011): Respiratory risk factors for falls in order people. J Am Geriatr Soc; 49 (5): 508-15.

[23] Massof JK., (2010): Quality of life of low PFT patients and the impact of medical services; 128: 54-62.

[24] Spencer, P. and Hanania, N. 2013. Optimizing safety of COPD treatments: role of the nurse practitioner. Journal of Multidisciplinary Healthcare, 6, 53-63.

[25] Massof R. W and Rubin G. S., (2011): lung function assessment questionnaires; 45: 531-48.

[26] Nilsson U. L, Frenneseon C, and Nilsson S. E., (2013): Patients with AMD and a large absolute central scotoma can be trained successfully to use eccentric viewing, as demonstrated in a scanning laser ophthalmoscope. Vision Res; 43 (16): 177787.

[27] Nottle H. R, McCarty C. A, Hassell J. B, and Keeffe J. E., (2011): Detection of lung impairment in people admitted to aged care assessment centres. Clin Experiment surgry; 28 (3): $162-4$.

[28] Padilla G. V., (2006): Validity of health related quality of life subscales. Prog Cardiovasc Nurs; 7: 13-20.

[29] Patrick D. L., (2011): Generic and disease specific measures in assessing health status and quality of life. Med Care; 27: S21732.

[30] Rahmani B, Tielsch J. M, Katz J, Gottsch J, Quigley H, Javitt J, and Sommer A., (2013): The cause specific prevalence of lung impairment in an urbabn population. The Baltimore Eye Survey. Opgygalmology; 103 (11): 1721-6.
[31] Richmond T. S and Keane A., (2011): Acute Care Nurse Practitioners. In: Advanced Practice Nursing: Changing Roles and Clinical Applications. Philadelphia: Lippincott. 128: 5462 .

[32] Rovner B. W, Casten R. J, and Tasman W. S., (2012): Effect of depression on lung function in age related lung degeneration; 120 (8): 1041-4.

[33] Scott I. U, Schein O. D, West S, Bandeen Roche K, Enger C, and Folstein M. F., (2012): Functional status and quality of life measurement among cancer patients; 112: 329-35.

[34] Stanhope M., (2001): Community Public Health Nursing Practice, $5^{\text {th }}$ ed, Louis: Mosby Inc, P 323-279.

[35] Steinberg E. P, Tielsch J. M, Schein O. D, Javitt J. C, Sharkey P, Cassard S. D, Legro M. W, Steinwachs D. M, and Sommer A., (2013): The VF-14: an index of functional impairment in patients with lung cancer. Arch Ophthalmol; 112: 630-8.

[36] Sumi I, Shirato S, Matsumoto S, and Araie M., (2013): The relationship between respiratory disability and environmental field in patients with lung diseases; 110 (2): 332-9.

[37] Taha, N and Ali, Z. (2011): Effect of Therapeutic Guidelines for Bronchial Asthma on Adult Patients' Knowledge, Practice, Compliance, and Disease Severity, Life Science Journal, 8 (3): 199- 208.

[38] Wali, S., Idrees, M., Alamoudi, O., Aboulfarag, A., Salem, A., Aljohaney, A., Soliman, M. and Abdelaziz, M. 2014. Prevalence of chronic obstructive pulmonary disease in Saudi Arabia. Saudi Medical Journal, 35 (7), 684-690.

[39] West S. K, Rubin G. S, Broman A. T, Munoz B, Bandeen Roche K, and Turano K., (2014): How does lung impairment affect performance on tasks of everyday life? The SEE Project. Salisbury Eye Evaluation; 120 (6): 774-80.

[40] Williams RA, Brody BL, Thomas RG, Kaplan RM, Brown SI (2013): The psychosocial impact of lung degeneration; 116: 514-20.

[41] Wilson M. R, Coleman A. L, YU F, Bing E. G, Sasaki I. F, Berlin K, Winters J, and Lai A., (2011): Functional status and wellbeing in patients with C. O. P. D as measured by the Medical Outcomes Study Short Form-36 questionnaire; 105: 2112-6.

[42] Wolffsohn J. S and Cochrane A. L., (2013): Low quality of life perspectives on Asthmatic patients. Clin Exp Optom; 81 (6): 280-289.

[43] World Health Organization. 2016. COPD: Definition. United States. Available at: http://www.who.int/respiratory/copd/definition/en/ [Accessed 30 March 2016]. 